\title{
Exposure to work-related sharp injuries among nurses in Nigeria
}

\author{
Prisca Olabisi Adejumo ${ }^{1}$, Busola Taofikat olatunji ${ }^{2}$ \\ 1. Department of Nursing, University of I badan, I badan, Nigeria. 2. College of Nursing, University of Illinois, Chicago, IL, \\ USA.
}

Correspondence: Prisca Olabisi Adejumo. Address: Department of Nursing, University of I badan, Ibadan, Nigeria. Email: bisiandbayo@yahoo.com

Received: September 15, 2013

DOI : $10.5430 /$ jnep.v4n1p229

Accepted: October 20, $2013 \quad$ Online Published: December 10, 2013

URL: http://dx.doi.org/10.5430/jnep.v4n1p229

\begin{abstract}
Workplace conditions increase risks to health care workers especially nurses who stay longest with the patient in the hospital. The purpose of this study was to determine the exposure to work-related sharp injuries among nurses and their frequency of contact with needles and other sharp devices at work in a selected Teaching hospital in Nigeria. Two hundred and seventy five (275) registered nurses participated in the study. Questionnaires served as the study tool and were administered following due ethical approval. Statistical analyses include descriptive and chi-square tests with the assistance of SPSS, version 18.

Findings showed several factors that constitute occurrence of sharp injury, according to $20 \%$ of the respondents, sharp injury occurred while they were administering injectable medicines and $35.3 \%$ of them identified needle recapping. To $21.2 \%$ and $11 \%$ of the participants, breakage of medication ampoule and packing used syringes and needles for disposal were identified respectively. Also, $87.6 \%$ of the respondents experienced sharp injury at work while $12.4 \%$ did not. The causes of sharp injury result from failure to follow recommended procedures through personal behavioural risks such as safe handling and disposal of needle and syringes. Nurses as the largest network of the health care enterprise need to be competent and up to date in their caring role to minimize sharp injuries at work and its sequelae.
\end{abstract}

\section{Key words}

Exposure to HIV, Work-related sharp injuries, Nurses, Nigeria

\section{I ntroduction}

Nigeria is the most populated country in sub-Saharan Africa, a region which carries the globe's heaviest burden of HIV/AIDS ${ }^{[1]}$. Although, the national median prevalence of HIV has taken a downward turn in recent years, the absolute number of people living with HIV has increased by almost half a million people in three years and AIDS related mortality has also slightly increased in the same time period to about 217,148 annual deaths attributed to AIDS according to Nigeria National Agency for the Control of AIDS (NACA) ${ }^{[2]}$. Human Immunodeficiency Virus (HIV) infection and AIDS in Nigeria therefore remains a major public health crisis in Africa's most populous nation which is home to more people living with HIV than any other country in the world, except South Africa and India ${ }^{[3]}$. The prevalence rate has increased 
progressively since the first reported case of HIV in Nigeria. HIV prevalence among adults aged 15-49 years, increased from $1.8 \%$ in 1991 to $5.8 \%$ in 2003, and in 2005, declined to $3.9 \%{ }^{[4]}$. Although the prevalence rate is lower than it is in South Africa, it is estimated that about 2.9 million people are living with the virus in Nigeria ${ }^{[6]}$. According to CIA World Factbook ${ }^{[7]}$, Africa is in an unfortunate position in the HIV and AIDS epidemic, as the 19 countries worldwide with the highest prevalence of reported infections are all African countries with more than 24.5 million, and more than $60 \%$ of the HIV-infected population.

In developing countries, where the prevalence of HIV infection is the highest in the world, the number of needle stick injuries is also the highest. Additionally, African health care workers suffer an average of two to four needle stick injuries per year ${ }^{[8]}$. Healthcare workers suffer many sharp injuries mostly needle sticks each year, Physicians are much less likely to report a needle stick injury than other healthcare professionals ${ }^{[7]}$. Estimates indicate that approximately only one out of three needle sticks are reported according to Wilburn ${ }^{[9]}$. While HIV/AIDS is now considered a chronic illness, a cure remains elusive, and the disease remains life threatening and more nurses are involved in the care of People Living with HIV and AIDS (PLWHA) across various healthcare settings. This is because as the prevalence declines, the number of people already infected does not decline correspondingly. The implication of this is that, nurses will increasingly be involved in caring for those already infected with HIV, and as such are at risk of exposure to infected sharps. This exposure through stick injury, while preventable are often accepted as being part of the job thereby nurses take on responsibilities for which they are ill prepared ${ }^{[9-11]}$.

Clinical patient care has though never been risk free. Historically, nurses and other health care providers have contracted cholera, yellow fever and influenza as a result of occupational exposure. Literature revealed ${ }^{[12-14]}$ that nurses' fear of contagion is associated with lack of knowledge about HIV and AIDS. Nonetheless, the occupational exposure to blood borne pathogens from accidental sharp injuries in health care settings continues to be a serious problem according to Ofili ${ }^{[15]}$. In another study, one hundred and fifty out of a cohort of 531 health care workers were followed up in the United States of America and it reported percutaneous or mucous membrane exposure to blood or body fluids from a patient with AIDS during the treatment of 238 of such patients ${ }^{[16]}$. Similarly, according to a Tanzanian study, five health care workers per year experienced percutaneous injuries ${ }^{[17]}$. Momah ${ }^{[18]}$, in her study of the epidemiology of needle stick and sharp injuries among health care workers in Nigerian hospitals found that $84.2 \%$ of the respondents had experienced at least one injury since embarking on their respective careers, while $62.2 \%$ of them sustained their recent injury within the past one year. Ofili et al. ${ }^{[19]}$ in their prospective study found out that the major accidents/injuries among nurses in their places of work were contact with patient's blood with ungloved hands, blood splashes on their faces and other parts of the body, needle pricks, cuts from drug ampoules, glove perforation during surgery and assault by violent/aggressive patients. The incidence of cutaneous exposures was higher than parenteral exposures.

Yet, knowledge about HIV mode of transmission has prompted a renewed appreciation of potential occupational exposure among healthcare workers especially among nurses in the selected setting. It is upon this background that this study was rooted to determine the exposure and frequency of contact with needles and other sharp devices at work by nurses in a selected Teaching Teaching hospital in Nigeria.

\section{Hypotheses}

- There is no significant relationship between exposure to work-related sharp injury and nurses professional qualification.

- There is no significant relationship between nurses' knowledge and attitude to work-related sharp injury prevention.

- There is no significant relationship between the level of education of nurses and their utilization of universal precaution against work-related sharp injury prevention. 


\section{Methods}

\subsection{Design, setting and sample}

This is a cross sectional descriptive survey which is part of a larger study investigating constraints in Nurses' use of HIV protective barriers as well as frequency of contact with sharp needles and occurrence of work-related sharp injury. This study took place in a tertiary hospital in Nigeria with a heavy work load for nurses. Often, maximum of 3-4 nurses work during the busiest (morning) shift in a 28 bedded ward and sometimes only 2 nurses.

Convenience sampling method was used to select eight out of the 26 wards in the setting as follows: Surgery and Paediatrics (18.2\%), Medicine (19.6\%), Obstetrics and Gynaecology (9.1\%), Accident and Emergency (8.7\%), Neurological ward, Ear, Nose and Throat (ENT), and Psychiatric wards (0.7\%). Purposive sampling technique was then employed to select all nurses who were willing, available for the study and met a criterion of direct patient care, they were 286 in number. A self administered questionnaire which has been developed following extensive literature review and researchers'personal observations during clinical interactions served as the study instrument. It was divided into five sections: Demographic data, Occurrence of sharp injury at work, Frequency of contact with needles or other sharp devices at work, Constraints in the care of PLWHA, Practice/compliance with universal precaution, and Care, Management, Communication and experience about PLWHA. The fit between the conceptual and operational definitions of the variables were examined for construct validity. The questionnaire sample was presented to some experts in HIV and AIDS research to ascertain its face and content validity. The methods used to measure the research variables were assessed for accuracy and consistency of information through a test retest method at three weeks interval. A correlation coefficient of 0.95 was obtained.

\subsection{Procedure for data collection}

An introductory letter from the Department of Nursing University of Ibadan was used to seek ethical approval from the Ethical Committee of the selected Teaching hospital, which was granted. Also, self introduction and explanation of the purpose of the research was carried out, after which the questionnaires were administered face to face during overlap period in the hospital and were retrieved immediately. Respondents' confidentiality was guaranteed before commencement of data collection.

\subsection{Data analysis}

Chi-square was used to test the formulated hypotheses and Spear man correlation using SPSS University of Illinois version 18 Computer Program. The quantitative data generated were subjected to descriptive analysis. Analysis of frequency with needles and other sharp devices at work was based on nurses reported contact with them. The mean from the classification criteria was used to calculate the level of sharp injury prevention practices or utilization of universal precautions. The score values below the mean are considered poor utilization while the score above the mean are considered good utilization of sharp injury prevention practices. For classification of practices of universal precautions, the research items used to elicit data were in 4-point likert scale. The responses were weighed on the bases of rank order of always (4 points), often ( 3 points), sometimes ( 2 points), and never (1 point). The summation of the 9 - items for each respondent form the score obtained.

\section{Results}

\section{Socio-demographic characteristics of the respondents}

Out of the 275 participants, there were 5 males (1.8\%) and 270 females (98.2\%). Majority (48.5\%) of the respondents were between 21 and 30 years old while the mean age of the respondents is 32 years and the standard deviation is 1.8. Additionally, 175 (63.6\%) were married while the remaining 100 (36.4\%) were single. Majority, 193 respondents (70.2\%) 
were Registered Nurse/Midwives. Most of them (62.2\%) had Diploma certificates, 13.8\% had Bachelor of Science in Nursing (BSc.) and only 1.5\% had non-specified post graduate degrees. Regarding working experience, 135 (49.1\%) of the respondents had 1-5 years working experience, and 16 (5.8\%) worked for 16-20 years while a small proportion, 6 (2.2\%) had worked for more than 20 years.

Table 1. Frequency of Contact with Needles and other Sharp Devices at work

\begin{tabular}{llll}
\hline VARIABLE & $\begin{array}{l}\text { Daily Contact } \\
\text { FREQ (\%) }\end{array}$ & $\begin{array}{l}\text { Occasional Contact } \\
\text { FREQ (\%) }\end{array}$ & $\begin{array}{l}\text { Rarely in Contact } \\
\text { FREQ (\%) }\end{array}$ \\
\hline Syringe with Needle & $219(79.6 \%)$ & $52(18.9 \%)$ & $4(1.5 \%)$ \\
Suture Needle & $12(4.4 \%)$ & $111(40.3 \%)$ & $152(55.3 \%)$ \\
IV Catheters & $111(40.4 \%)$ & $121(44.0 \%)$ & $43(15.3 \%)$ \\
Lancet & $37(13.5 \%)$ & $155(56.4 \%)$ & $83(30.2 \%)$ \\
Scalpel & $132(48.0 \%)$ & $108(39.3 \%)$ & $35(12.7 \%)$ \\
Medication Vial & $191(69.5 \%)$ & $75(27.3 \%)$ & $9(3.3 \%)$ \\
Specimen (Capillary/Test tube) & $120(43.6 \%)$ & $102(37.1 \%)$ & $53(19.3 \%)$ \\
Scissors & $226(82.2 \%)$ & $38(13.8 \%)$ & $11(4.0 \%)$ \\
Pick-Ups/ Forcep/Haemostat/ Clamp & $165(60.0 \%)$ & $82(29.8 \%)$ & $28(10.2 \%)$ \\
Glass Slide & $66(24.0 \%)$ & $126(45.8 \%)$ & $83(30.2 \%)$ \\
\hline
\end{tabular}

From Table 1, majority (82.2 \%) of the respondents had contact with scissors and $79.6 \%$ of the respondents had contact with syringe with needle on daily basis.

Table 2. Respondents’ Sharp injury Prevention Practices.

\begin{tabular}{|c|c|c|c|c|c|}
\hline & Never & Sometimes & Often & Always & TOTAL \\
\hline $\begin{array}{l}\text { I protect myself against blood and body fluids of all } \\
\text { patients regardless of their diagnosis. }\end{array}$ & - & $9(3.3 \%)$ & $33(12 \%)$ & 233(84.7\%) & $275(100 \%)$ \\
\hline $\begin{array}{l}\text { I put used needles and other sharp objects into the } \\
\text { designated sharps containers. }\end{array}$ & $8(2.9 \%)$ & $35(12.7 \%)$ & $37(13.5 \%)$ & 195(70.9\%) & $275(100 \%)$ \\
\hline $\begin{array}{l}\text { I wear gloves whenever there is a possibility of } \\
\text { exposure to blood or other body fluid. }\end{array}$ & $5(1.8 \%)$ & $20(7.3)$ & $12(4.4 \%)$ & $238(86.5 \%)$ & $275(100 \%)$ \\
\hline $\begin{array}{l}\text { I wear eye protective (goggles/glasses) whenever } \\
\text { there is possibility of blood or other body fluids } \\
\text { splashing on my face. }\end{array}$ & $156(56.7 \%)$ & $50(18.2 \%)$ & $17(6.2 \%)$ & $52(18.9 \%)$ & $275(100 \%)$ \\
\hline $\begin{array}{l}\text { I do not recap needles that have been contaminated } \\
\text { with blood or used on body fluids. }\end{array}$ & $74(26.9 \%)$ & $57(20.7 \%)$ & $29(10.5 \%)$ & $115(41.8 \%)$ & $275(100 \%)$ \\
\hline $\begin{array}{l}\text { I promptly wipe up all spills of blood and other body } \\
\text { fluids with disinfectants. }\end{array}$ & $8(2.9 \%)$ & $34(12.3 \%)$ & $39(14.2 \%)$ & $184(66.9 \%)$ & $275(100 \%)$ \\
\hline I cover my broken skin before coming to work & $6(2.1 \%)$ & $17(6.2 \%)$ & $31(11.3 \%)$ & $221(80.4 \%)$ & $275(100 \%)$ \\
\hline $\begin{array}{l}\text { I report needle stick injury when I have such on a } \\
\text { record sheet/book. }\end{array}$ & $115(41.8 \%)$ & $42(15.3 \%)$ & $30(10.9 \%)$ & $88(32 \%)$ & $275(100 \%)$ \\
\hline $\begin{array}{l}\text { I obtain PEP treatment after exposure to needle stick } \\
\text { and sharp injury when caring for PLWHA }\end{array}$ & $161(58.5 \%)$ & $6(2.2 \%)$ & $17(6.2 \%)$ & $33(12.0 \%)$ & $\begin{array}{l}275(78.9 \%) \\
21.1 \% \text { were } \\
\text { missing data }\end{array}$ \\
\hline
\end{tabular}

Up to $21.1 \%$ decline responding to this question and that may probabably be due to inaction after possible exposure.

\section{Participants' knowledge of work-related sharp injuries}

There are several factors that constitute wok-related sharp injury, most of the respondents had knowledge of these, $20 \%$ of them identified that exposure to sharp injury occurred while administering injectable medicines and 35.3\% of them 
identified attempt to recap needle, $21.2 \%$ of them identified attempt to break medication ampoule and $11.1 \%$ of them identified packing used syringes and needles for disposal.

Similarly, another question was asked about circumstances leading to sharp injury for confirmation of responses. The result shows that $40.3 \%$ of the respondents described attempting to recap needle, $23.9 \%$ of them described attempting to meet patient's needs in a hurry due to shortage of staff, $12.9 \%$ of the respondents implicated careless placement of uncapped needle, explanation of $10 \%$ of the respondents was while attempting to recap punctured infusion bag with needle and $0.5 \%$ of the respondents described scrubbing (passing of equipment during surgery) in the operating theatre. In sum, $87.6 \%$ of the respondents have had contact with and experienced sharp injuries at work.

Table 3. Knowledge about work-related sharp injuries prevention practices

\begin{tabular}{|c|c|c|c|}
\hline & RESPONSE & FREQ & $\%$ \\
\hline $\begin{array}{l}\text { Application of universal precaution is necessary to protect Nurses from exposure \& } \\
\text { contracting HIV infection. }\end{array}$ & Yes & 261 & 94.9 \\
\hline Have you attended any infection control course or training programme. & Yes & 117 & 42.5 \\
\hline \multirow{5}{*}{$\begin{array}{l}\text { How would you rate the information given to you about protection from HIV infection } \\
\text { and other blood borne viruses. }\end{array}$} & Very Satisfactory & 19 & 6.9 \\
\hline & Satisfactory & 82 & 29.8 \\
\hline & 'Unsatisfactory & 16 & 5.8 \\
\hline & No Information & 158 & 57.5 \\
\hline & TOTAL & 275 & 100 \\
\hline \multirow{4}{*}{$\begin{array}{l}\text { Not doing HIV screening for clients whose care may expose you as a Nurse to blood or } \\
\text { body fluids as a pre-requisite puts you at risk. }\end{array}$} & Yes & 210 & 76.4 \\
\hline & rNo & 31 & 11.3 \\
\hline & Not Sure & 34 & 12.4 \\
\hline & TOTAL & 275 & 100 \\
\hline \multirow{5}{*}{ Precaution need to be taken when handling body fluids of PLWHA } & Yes & 264 & 96.0 \\
\hline & No & 1 & 0.4 \\
\hline & Not Sure & 2 & 0.7 \\
\hline & Don’t Know & 8 & 2.9 \\
\hline & TOTAL & 275 & 100 \\
\hline \multirow{4}{*}{ Post exposure prophylaxis (PEP) for HIV is available in this hospital } & Yes & 154 & 56.0 \\
\hline & No & 6 & 2.2 \\
\hline & Not Sure & 115 & 41.8 \\
\hline & TOTAL & 275 & 100 \\
\hline \multirow{4}{*}{$\begin{array}{l}\text { It is necessary to obtain PEP immediately after a sharp injury or needle stick from } \\
\text { PLWHA when caring for them. }\end{array}$} & Yes & 233 & 84.7 \\
\hline & No & 0 & 0 \\
\hline & Not Sure & 42 & 15.3 \\
\hline & TOTAL & 275 & 100 \\
\hline
\end{tabular}

Table 3 shows that $94.9 \%$ of the respondents identified that in HIV/AIDS care and management, application of universal precaution is necessary to protect nurses from exposure \& contracting HIV infection while $5.1 \%$ did not see the need for application of universal precaution.

\section{Discussion}

Based on the study objectives, exposure to work related sharp injuries occurred among study participants while administering injectable medication (23\%), while recapping needle (42.3\%), during breaking of medication ampoules (22.6\%) and $12.1 \%$ while packing used syringes and needles for disposal. These findings correspond to the study of Wilson ${ }^{[20]}$ who 
stated that the causes of sharp injury result from failure to follow recommended procedures through personal behaviour than professional risk such as safe handling and disposal of needles and syringes. The result showed that $28.9 \%$ of the respondents described attempting to meet patient's needs in a hurry due to inadequate staffing in a pressured environment, $12.4 \%$ of the respondents described attempting to recap puncture infusion bag with a needle and $0.5 \%$ of them implicated scrubbing (passing of equipment) in the operating room. In sum, $87.6 \%$ of the respondents have been exposed to sharp injury at work. This is dangerous to the individual nurse and her family by extension, other patients as well as the larger society. This finding corresponds to the study done by Clarke et al. ${ }^{[21]}$, about relationship between work organizational factors such as short staffing, poor safety climate and needle-stick injury. Other authors similarly supported this finding ${ }^{[5,22,23]}$.

Determining the frequency of contact and exposure of participants to needles and other sharp injuries at work, series of items such as scissors, needles and syringes as shown in Table 1 were implicated. In agreement with this, the most common item that can cause exposure to work-related injuries in hospitals involved hollow bore needles which were the most risky because the needle can be filled with blood according to Centers for Disease Control and Prevention (CDC) ${ }^{[24]}$. This includes: manipulating the needle in the patient (26\%), disposal (23\%), collision with other workers or sharps during clean-up (10\%), accessing IV line (6\%), and recapping needles (6\%).

Determining means of sharp injury prevention among the study participants and investigating their frequency and exposure to needles and other sharp devices at work in the setting, respondents agreed that application of universal precaution is necessary to protect them from exposure to work related sharp injury (see Table 2 and 3). It is expected that every nurse should understand that prevention practices are necessary to protect them from exposure to work related sharp injuries and possibilities of contracting HIV infection. Effective needle stick injury prevention measures include administrative and work practice controls such as educating workers about hazards, implementing universal precautions, eliminating needle recapping and providing sharps containers for easy access that are within sight and arm's reach ${ }^{[25,26]}$. In a study involving three Virginia hospitals, Jagger ${ }^{[27]}$ found $95.9 \%$ reduction in IV access needle injuries following an educational program and implementation of universal precautions. There was an additional $84 \%$ reduction in injuries after implementation of a safe IV Catheter ${ }^{[27]}$. Management commitment to occupational health is therefore important for prevention, which can be demonstrated through allocation of necessary resources and delegation of authority to a needle stick prevention committee charged with monitoring and exposure control plan and the evaluation and selection of control measures including safer needle devices ${ }^{[26]}$.

Furthermore, prevention of needle stick and other sharp injury is possible by analyzing the hazards and applying control measures using a hierarchy of controls starting with the elimination of unnecessary sharps and injections to eliminate the hazard. Needleless IV systems, recommended by Gershon et al. ${ }^{[28]}$, Fisher ${ }^{[29]}$ and Yassi et al. ${ }^{[30]}$ are also documented in literature. Eliminating unnecessary injections by using oral instead of injectable medication eliminates the hazard further according to Adejumo and Dada ${ }^{[31]}$. Engineering controls are the second most effective measures. The 2000 U.S. needle safety and prevention act established the requirement for healthcare settings to use engineering controls known as safer needle device OSHA ${ }^{[32]}$ which have been shown to reduce needle stick injuries.

In addition, 57.5\% of the respondents have attended infection control course or training programmes while $42.5 \%$ of them did not. Also, majority of the participants, $41.8 \%$ agreed that they never reported sharp injuries. This showed high level of knowledge deficit as found in a study by Wang et al. ${ }^{[33]}$. According to information from the Department of Health (DOH) ${ }^{[34]}$, a member of staff who has been exposed to the source patient must seek urgent advice from an expert concerning the risk of infection and potential 'benefit' of Post Exposure Prophylaxis (PEP).

From the tested hypotheses, hypothesis one on exposure to work-related sharp injury and professional qualification of participants was not supported. Hence, a significant relationship exists between work-related sharp injury devices and professional qualification of participants. Hypothesis two which states that there was no significant relationship between 
nurses' knowledge and attitude to work-related sharp injury prevention was also not supported. There was a significant relationship between the knowledge of professional and their attitude to sharp injury prevention. Same applies to the third hypothesis on the participants' level of education and their utilization of universal precaution against work-related sharp injury prevention, lack of training about occupational prevention of blood borne pathogens may place nurses at risk in clinical practice ${ }^{[31]}$. In Nigeria, workplace conditions, such as poor lighting, lack of appropriate protective materials and out dated techniques such as needle recapping as revealed in this study increases the risk of nurses' exposure to sharp injuries ${ }^{[35]}$. Unreported needle stick and sharp injuries are a serious problem and prevent injured health care workers from receiving post-HIV exposure prophylaxis shown to be $80 \%$ effective against HIV infection.

\section{Nursing implications}

From this study it was evident that gaps still exist in reporting work-related needle stick injury and obtaining post exposure prophylaxis treatment among study participants. As nurses perform skills which may expose them to occupational risk of sharp injuries such as administering injectable medicines to patients, wound dressing in clinical or emergency settings, scrubbing in the operating room and so on, there is a dire need for continuous training and retraining on current issues about HIV/AIDS and treatment after which a follow up and proper supervision should be done to ensure that nurses actually utilize what they have acquired from various trainings. More so, improved knowledge, behaviour change and extreme care in handling and disposal of needles and sharps will go a long way in preventing the occurrence of work-related sharp injury. Nurses as patient care advocate should also help in educating their colleagues and other members of the health care team such as the doctors on the dangers of leaving needles and other sharps on patient beddings. Hospital management should acquire engineered controlled needles and syringes which minimize the risk of work-related sharp injuries among all health care workers.

\section{References}

[1] Nigeria National Agency for the Control of AIDS. National HIV/AIDS Strategic Plan 2010 -2015. Abuja Nigeria: Nigeria National Agency for the Control of AIDS, 2010.

[2] Federal Ministry of Health. National HIV Sero-prevalence Sentinel Survey Among Pregnant Women Attending Antenatal Clinics in Nigeria. Abuja Nigeria: Federal Ministry of Health, 2010.

[3] WHO/UNAIDS. AIDS epidemic update; special report on HIV/AIDS. WHO/UNAIDS; 2006.

[4] Federal Ministry of Health (FMoH), Nigeria, HIV/AIDS; what it means for Nigeria (background, Projections, impact, intervention \& policy), December, 2002.

[5] American Nurses Association. ANA’s needle stick prevention guide. 2000. www.nusingworld.org/needlestick/needleguide;http:/www.nusingworld.org/needlestick/needleguide

[6] UNAIDS (2004); Epidemiological fact sheet Nigeria, update

[7] Directorate of Intelligence (2011-07-12). "CIA - World Factbook". Retrieved 2011-07-14. "The World Factbook provides information on the history, people, government, economy, geography, communications, transportation, military, and transnational issues for 267 world entities." Retrieved 2011.

[8] Prass Ustun, A., Rapiti, E., \& Hutin, Y. Sharp injuries: Global burden of disease from sharps injuries to health - care workers. Geneva, Switzerland: World Health Organization, 2003.

[9] Eucomed. European health care workers at risk! Retrieved May 13, 2004 from www.eucomed.be/?x=4\&y=46\&z=118, 2004.

[10] Wilburn, S. Preventing needlestick injuries. In protecting the health and safety of health care workers. Washington, D. C. American Nurses Publishing, 2004.

[11] WHO, UNAIDS, ICN: Fact sheets on HIV/AIDS for Nurses and Midwives. Geneva, WHO, 2000.

[12] Grellier R: Midwives' knowledge of the HIV virus and its implication for their attitudes and practice. Royal Council of Midwives Journal. 1997; 110(1315): 190-193.

[13] Ndikom CM \& Onibokun, AC. Knowledge and behaviour of nurse/midwives in the prevention of vertical transmission of HIV in Owerri, Imo State, Nigeria: a cross-sectional study, 2007.

[14] Meisenhelder, J.B. Contributing factors to fear of HIV contagion in registered nurses. Image: Journal of Nursing Scholarship. 1994; 26: 65-69. http://dx.doi.org/10.1111/j.1547-5069.1994.tb00296.x 
[15] Ofili AN. Occupational accidents among hospital workers at the Central Hospital, Benin City, Edo State, Nigeria. A dissertation accepted by the Faculty of Public Health, National Postgraduate Medical College, November 2000; 70-84.

[16] Henderson DK, Saah AJ, Zak BJ, et al. Risk of nosocomial infection with human T-cell lymphotropic virus in a large cohort of intensively exposed health care worker. Ann Intern Med. 1986; 104: 644-647. PMid:3963663 http://dx.doi.org/10.7326/0003-4819-104-5-644

[17] WHO. Monitoring the AIDS Pandemic. The Status and Trends of the HIV/AIDS Epidemics in the World Provisional Report. Geneva: Switzerland. 1998; 17-18.

[18] Momah PH. The epidemiology of needle stick and sharp injuries among health workers in Nigerian hospitals. Report of a project. Faculty of Public Health, National Postgraduate Medical College, 1992; 102.

[19] Ofili AN, Asuzu MC and Okojie OH. Incidence of blood-related work accidents among health workers in a government hospital in Benin City, Nigeria. Journal of Medicine and Biomedical Research. 2004; 3(1): 59-66.

[20] Wilson J; Infection Control in Clinical Practise. 2nd edition. Bailliere Tindall London.

[21] Clarke S. P., Sloane, D.M., \& Aiken, L. Effects of hospital staffing and organisational climate on needle stick injuries to Nurses. American Journal of Public Health. 2002; 92(7): 1115-1119.

[22] Buve A, Foster S.O, Mbrili C. Mortality among female Nurses in the face of the AIDS Epidemic: a pilot study in Zambia. 1994; 8: 396. http://dx.doi.org/10.2105/AJPH.92.7.1115

[23] Dale J. C., Pruett S. K., Maker M. D. Accidental needle stick in the phlebotomy service of the Department of Laboratory Medicine and Pathology at Mayo Clinic, Rochester, 1998.

[24] Centres for Disease Control and Prevention. Workbook for designing, implementing and evaluating a sharp injury prevention programme, 2004.

[25] Haiduven, D. J., DeMaio, R. M., \& Stevens, D. A. A five - year study of needle stick injuries: Significant reduction associated with communication, education, and convenient placement of sharps containers. Infection Control Hospital Epidemiology. 1992; 13: 265-271. PMid:1593109 http://dx.doi.org/10.1086/646525

[26] Olatunji, Adejumo, P.O., and Adejumo, A.O. Constraints in Nurses' use of HIV Protective Barriers (PB) in the Care of PLWHA in the University College Hospital (UCH), Ibadan, Nigeria. The Official Journal of the International Hospital Federation, June, 2009.

[27] Jagger, J. Reducing occupational exposure to blood borne pathogens. Where do we stand a decade later? Infection Control Hospital Epidemiology. 1996; 17(9): 573-575.

[28] Gershon, R. R., Karkashian, C. D., Grosch, J. W., Murphy, L. R., Escamilla-Cejudo, Gartner, K. Impact of a needleless intravenous system in a University Hospital, 1992. PMid:8880228 http://dx.doi.org/10.1086/647384

[29] Fisher, J. Strategies for integrating health care workers into the process of design, selection and use of control technology. In W. Charney \& J. Schirmer (Eds.), 1994.

[30] Yassi, A., McGill, M. L. \& Knokhar, J. B. Efficacy and cost effectiveness of a needleless intravenous system. American Journal of Infection Control. 1995; 23: 57-64. http://dx.doi.org/10.1016/0196-6553(95)90095-0

[31] Adejumo, P.O and Dada, F.A. A comparative study on knowledge, attitude, and practice of injection safety among nurses in two hospitals in Ibadan, Nigeria. International Journal of Infection Control. 2013; 9(1). http://dx.doi.org/10.3396/ijic.v9i1.004.13

[32] OSHA. Occupational exposure to bloodborne pathogens - Occupational Safety and Health Administration: final rule. Federal Register. 1991; 56(235): 64004-64182. PMid:10115865

[33] Wang H., Fenniek, H. E. G., Burgess, J. \& Williams, A. E. Journal of Advanced Nursing. 2003; 41(2): 187-194. PMid:12519278 http://dx.doi.org/10.1046/j.1365-2648.2003.02519.x

[34] Department of Health (2004); HIV Post Exposure Prophylaxis. DOH. London.

[35] Osborn, E. H. S., Papadakis, M. A. \& Gerberding, J. L. Occupational exposures to body fluids among medical students: A seven year longitudinal study. Annal of internal medicine. 1999; 130: 45-51. 